Image Article

DOI: $10.36959 / 582 / 423$

\title{
Pseudoaneurysm Formation of the Ascending Aorta
}

\author{
E Andreas Agathos, $M D, P h D^{1^{*}}$, George Anastasiadis, $M D^{1}$ and Angeliki Saridaki, $M D^{2}$
}

${ }^{1}$ Department of Cardiac Surgery, Euroclinic of Athens, Greece

${ }^{2}$ Department of Cardiac Anaesthesia, Euroclinic of Athens, Greece

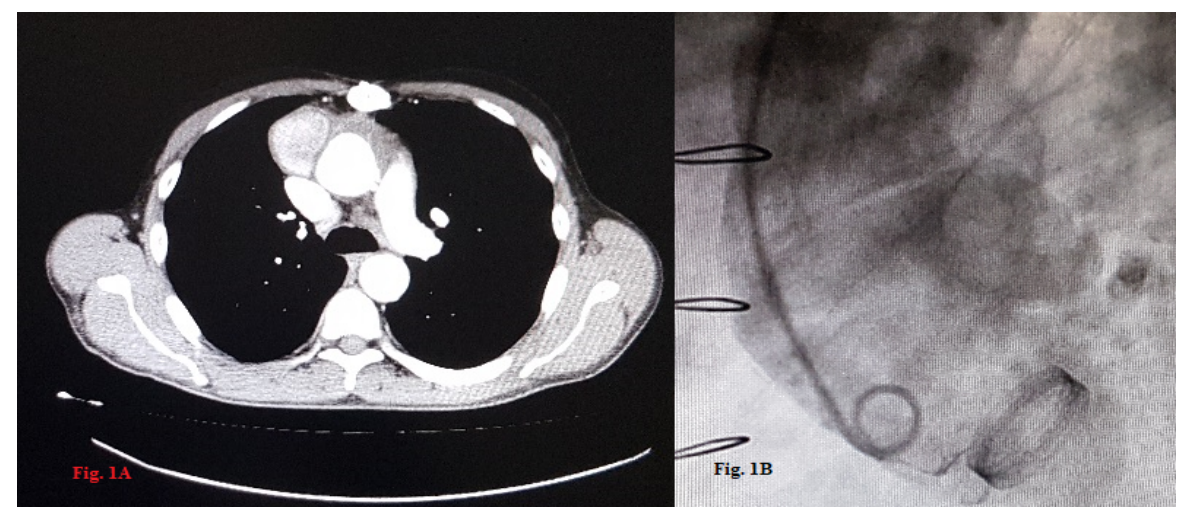

Figure 1: Investigation with CT angiogram and aortogram.

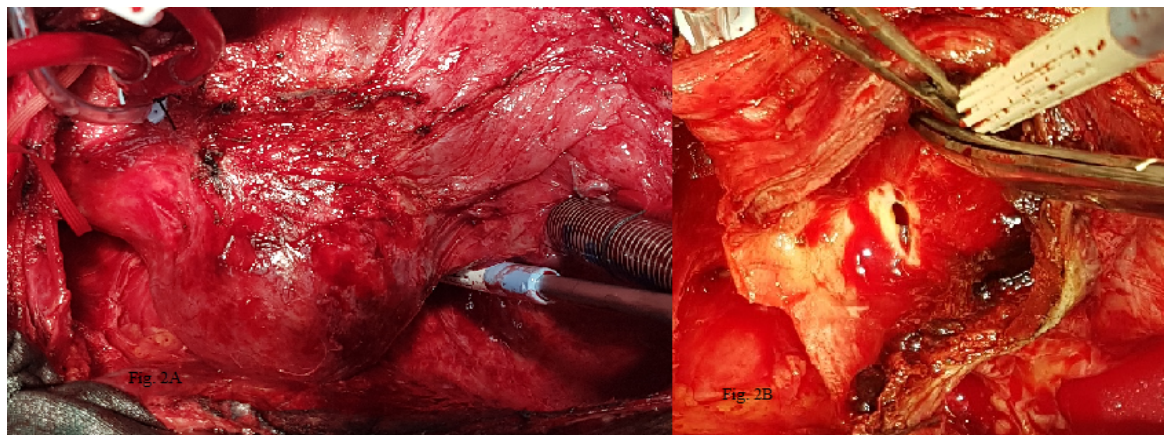

Figure 2: A pseudoaneurysm formation and resection of the wall.

A 50-years-old male patient, hypertensive, on renal dialysis and with secondary hyperparathyroidism, underwent aortic valve replacement with a \#23 mm Sorin bileaflet mechanical prosthesis. Three months later he had a redo operation to fix a perivalvular leak. There was no evidence of infection. A year later he was referred to us with an asymptomatic paraortic mass in a CT Thorax. Further investigation with $\mathrm{CT}$ angiogram (Figure $1 \mathrm{~A}$ ) and aortogram (Figure 1B) revealed a $5.5 \times 4.8 \mathrm{~cm}$ mass in close proximity to the middle and lateral aspect of the ascending aorta, filling with contrast fluid. During the third operation, a pseudoaneurysm formation was confirmed (Figure 2A). Resection of the wall of the sac revealed a dehiscence $4 \times 4 \mathrm{~mm}$ at the lateral angle of the previous aortotomy (Figure $2 \mathrm{~B}$ ) due to broken $4 / 0$ prolene stich. The dehiscence was repaired with two $2 / 0$ pledgeted ethibond stiches. Uncomplicated recovery. No evidence of recurrence 12 months following surgery.

\section{Conflict of Interest}

The Authors declare that there is no conflict of interest.

*Corresponding author: $\mathrm{E}$ Andreas Agathos, MD, PhD, Department of Cardiac Surgery, Euroclinic of Athens, Athanassiadou 7-9, 11521 Athens, Greece, Tel: 30-2106801237

Accepted: June 15, 2020

Published online: June 17, 2020

Citation: Agathos EA, Anastasiadis G, Saridaki A (2020) Pseudoaneurysm Formation of the Ascending Aorta. J Cardiothorac Surg Ther 2020:4(1):57 